\title{
COMPARATIVE REPORT ON PULMONARY FUNCTIONS IN RURAL AND URBAN WOMEN IN WESTERN MAHARASHTRA, INDIA- A TIME FOR SCREENING RURAL POPULATION?
}

\author{
Medha Deepak Bargaje1, Saurabh Singh², Anita Tulshiramji Anokar³, Ram Balakrishna Deoskar4, Shrivallabh Sane ${ }^{5}$
}

1Professor, Department of Pulmonary Medicine, Bharati Vidyapeeth Deemed University Medical College and Hospital, Pune, Maharashtra.

${ }^{2}$ Resident, Department of Pulmonary Medicine, Bharati Vidyapeeth Deemed University Medical College and Hospital, Pune, Maharashtra.

${ }^{3}$ Assistant Professor, Department of Pulmonary Medicine, Bharati Vidyapeeth Deemed University Medical College and Hospital, Pune, Maharashtra.

4Professor and HOD, Department of Pulmonary Medicine, Bharati Vidyapeeth Deemed University Medical College and Hospital, Pune, Maharashtra.

${ }_{5}^{5}$ Biostatistician, Department of Community Medicine, Bharati Vidyapeeth Deemed University Medical College and Hospital, Pune, Maharashtra.

\begin{tabular}{l}
\hline ABSTRACT \\
\hline BACKGROUND \\
Around 3 billion people still cook and heat their homes using solid fuels (i.e. wood, crop wastes, charcoal, coal and dung) in open \\
fires and leaky stoves. Most are poor and live in low- and middle-income countries. In rural India, nearly $90 \%$ of the primary energy \\
is derived from biomass (wood, 56\%; crop residues, 16\%; dung, 21\%). \\
We took up this study with an aim to compare the lung functions of both rural and urban population in Maharashtra, India.
\end{tabular}

\section{MATERIALS AND METHODS}

324 rural women and 253 urban women in Maharashtra, India, were interviewed with a standard respiratory questionnaire and their pulmonary function test was performed using portable computerised spirometer.

\section{RESULTS}

The comparative pulmonary function parameter based on the pulmonary function testing in rural and urban women showed significant lung function abnormalities (FEV1, FEV1/ FVC, PEFR, MEF 25-75) in rural women exposed to biomass fuel as compared to urban women who use LPG (Liquefied Petroleum Gas) for cooking.

\section{CONCLUSION}

Biomass fuel exposure poses a great impact on lung functions of rural women. Factors like poor ventilation in kitchen, lack of screening programs and late manifestation of disease cause irreversible damage to lung functions.

\section{KEYWORDS}

Lung Function; Biomass Fuel; Rural Population; Urban Population; Indoor Pollution.

HOW TO CITE THIS ARTICLE: Bargaje MD, Singh S, Anokar AT, et al. Comparative report on pulmonary functions in rural and urban women in western Maharashtra, India- a time for screening rural population? J. Evolution Med. Dent. Sci. 2017;6(91):64546459, DOI: $10.14260 /$ jemds/2017/1403

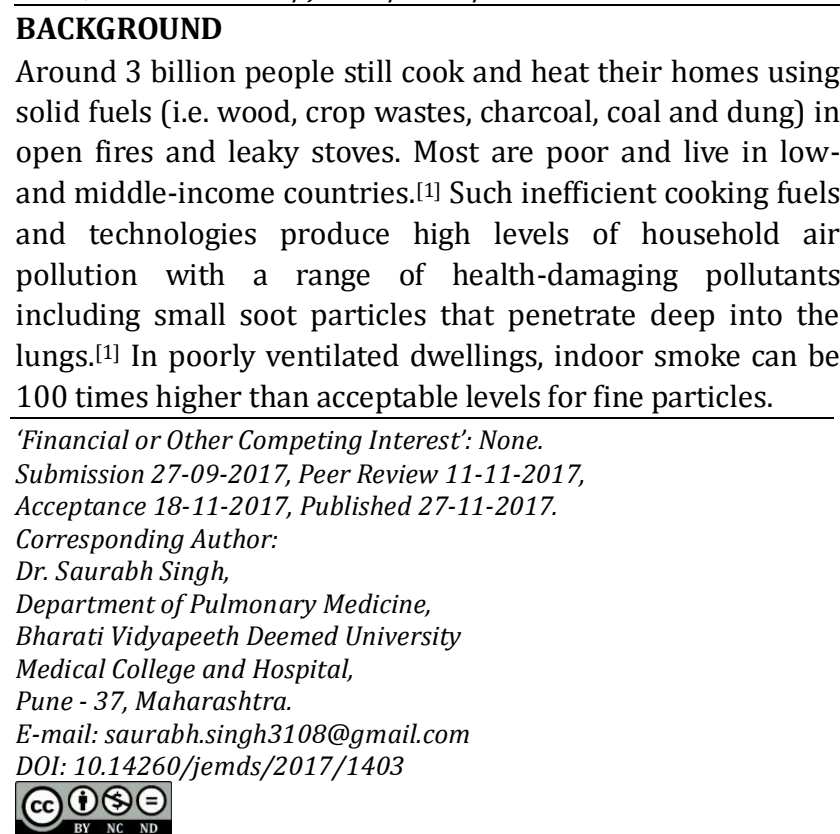

Exposure is particularly high among women and young children, who spend the most time near the domestic hearth.[1]

In rural India, nearly $90 \%$ of the primary energy is derived from biomass (wood, 56\%; crop residues, $16 \%$; dung, $21 \%$ ).[2] The majority of rural households in developing countries burn biomass fuels in open fireplaces or in nonairtight stoves, resulting in substantial emissions which in the presence of poor ventilation produce very high levels of indoor pollution with 24-hour mean PM10 levels in the range of 300 to $3,000 \mathrm{mg} / \mathrm{m} 3$, which may reach $30,000 \mathrm{mg} / \mathrm{m} 3$ during periods of cooking. ${ }^{[3-4]}$

A significant number of these wood smoke constituents are known to be toxic or irritants for the respiratory system including respirable PM (PM10), carbon monoxide (CO), nitrogen and sulfur oxides (NO2, SO2), aldehydes (e.g. formaldehyde), polycyclic aromatic hydrocarbons (e.g. benzopyrene), volatile organic compounds, chlorinated dioxins and free radicals.[5-8] Many substances can act as primary pollutants, irritants and carcinogenic or cocarcinogenic compounds. ${ }^{[7]}$ 
Central Pollution Control Board, which monitors continuous ambient air quality at Navi Mumbai Municipal Corporation Airoli shows an alarming level of respirable PM (PM10 and PM 2.5).[9]

The World Health Organisation (WHO) estimates that around 4.3 million people every year die prematurely from illness attributable to the household air pollution caused by the inefficient use of solid fuels (2012 data) for cooking.[1]

\section{Among these Deaths}

- $12 \%$ were due to pneumonia.

- $34 \%$ from stroke.

- $26 \%$ from ischaemic heart disease.

- $22 \%$ from chronic obstructive pulmonary disease (COPD)

- $6 \%$ from lung cancer.

A multicentric Indian study on Epidemiology of Asthma, Respiratory symptoms and Chronic Bronchitis (INSEARCH) has been conducted, which concluded that Asthma and Chronic Bronchitis in adults pose an enormous health care burden in India. Most of the associated risk factors are preventable.[10]

Though the urban population is mostly free from biomass exposure and mainly rely on liquefied petroleum gas (LPG) for cooking, external factors like open-air burning of waste, industrial and vehicular pollution pose an impact on lung functions of urban population as studied in numerous studies. Considering the well-studied and documented evidence regarding biomass exposure in the rural population, we took up this study with an aim to compare the lung functions of both rural and urban population in Maharashtra to look for insights of pulmonary functions in both populations.

\section{MATERIALS AND METHODS}

\section{Study Design}

It is a cross-sectional observational study studied over rural and urban population of western Maharashtra.

\section{Study Population and Sampling}

Rural health camps were conducted in 3 different villages named Utroli, Wing and Bajarwadi of Pune and Satara District of Maharashtra. Similarly, health camps were conducted in Pune City and Navi Mumbai of Maharashtra for urban women sampling. We included all women coming to our health camp from the age group of 18 - 60 years in both rural and urban populations. 324 rural women and 253 urban women were selected for the study meeting for our inclusion criteria, whereas all others were excluded from our study. Sample size of 577 subjects was calculated for the study based on the following factors: An expected $2.55 \%$ prevalence of COPD for women in Maharashtra; desired confidence level of $(\alpha)$ of 0.05 ; power of the study $(1-\beta)=0.80$ : and design effect $=2$ and by using 2 independent sample proportion formula-

$\mathrm{n}=\left(\mathrm{Z}\right.$ a $+\mathrm{Z}(1-\beta)^{2} *(\mathrm{p} 1 \mathrm{q} 1+\mathrm{p} 2 \mathrm{q} 2) / \mathrm{d}^{2}$

$\mathrm{n}=$ sample size; $\mathrm{Z} \mathrm{a}=$ Standard normal variation for $\mathrm{a}=0.05$ $(95 \% \mathrm{CI})$

Z1- $\beta=$ Standard normal variate for $1-\beta=0.80(80 \%) ; p 1=$ proportion (\%) in one group;

$\mathrm{q} 1=100-\mathrm{p} 1$ and similarly for $\mathrm{p} 2 ; \mathrm{d}=\mathrm{p} 1-\mathrm{p} 2$
Over the duration of study period, we studied the total number of 577 subjects and the distribution of Rural and Urban is by chance.

\section{Inclusion Criteria}

1. Age $18-60$ years.

2. Non-smoker.

3. Performance of spirometry meeting American Thoracic Society (ATS)/ European Respiratory Society (ERS) criteria.

4. Answers to standard respiratory questionnaires.

5. Willingness to enrol in the study with written consent.

\section{Exclusion Criteria}

1. Pregnant women.

2. History of active respiratory infections and cardiovascular diseases.

3. Recent MI (3 - 6 months).

4. Recent stroke, eye surgery, thoracic/ abdominal surgery.

5. Haemoptysis.

6. Known thoracic, aortic or cerebral aneurysm.

7. Recent pneumothorax.

8. Uncontrolled hypertension.

9. Pulmonary embolism.

10. Denial for enrolment in the study.

Villages selected were within the radius of 50 kilometres from Pune city and were free from industrial pollution and with negligible vehicular pollution, so as to avoid the confounding factors. These villages have an average of 1100 women population according to 2011 census.

These subjects were interviewed with a standard respiratory questionnaire based on multicentre study "Indian study on Epidemiology of Asthma, Respiratory Symptoms and Chronic Bronchitis (INSEARCH)." The questionnaire focused on occupation, use of the type of biomass fuel, ventilation inhouse, hours of exposure to biomass fuel, etc.

\section{Pulmonary Function Test}

Pulmonary function of these subjects was estimated using computerised pulmonary function testing device (EasyOne). To ensure the accuracy of the reading, the devices were calibrated regularly.

As per standard guidelines, the height and weight were measured and the technique was explained and demonstrated prior to the testing. Best of three readings was recorded meeting the ATS (American Thoracic Society)/ ERS (European Respiratory Society) criteria for the flow-volume loop.

The standard predicted value based on Global Initiative for Obstructive Lung Disease (GOLD) guidelines were considered and lung function values were further classified as the GOLD 1 - 4 severity of Chronic Obstructive Pulmonary Disease (COPD).[11]

\section{Statistical Analysis}

The type of data is quantitative and qualitative. The relevant clinical, microbiology and long-term outcome data collected was summarised into tables and graphs and was analysed using Microsoft Excel and SPSS (Version 20.0) software with 
the help of biostatistical whenever required. Nominal data such as demographic data and symptoms were presented as frequency (n) and percentage (\%). Bivariate analyses were conducted using the Chi-square or Fisher's exact test where appropriate. A p-value $\leqslant 0.05$ was considered statistically significant in all analyses.

\section{Ethics}

Our study was approved by our Institutional Ethics Committee and is in accordance with Helsinki statement.

\section{Key Definitions}

- Values for the FEV1, FVC and PEFR must be compared with the predicted normal values which depend on the individual's age, height and sex.

- $\quad$ FEV1 (forced expired volume in one second): volume expired in the first second of maximal expiration after a maximal inspiration. It is an important tool for assessment of lung function.

- FEV1/ FVC: FEV1 expressed as a percentage of the FVC, gives a clinically useful index of airflow limitation.

- $\quad$ A FEV $1<80 \%$ predicted and the FEV1/ FVC ratio $<0.70$ shows airflow limitation.

- GOLD severity of COPD (In patients with FEV1/ FVC ratio $<0.70$ ).

- GOLD 1; Mild: FEV1 is $\geq 80 \%$ predicted.

- GOLD 2; Moderate: FEV1 is 50\% - 79\% predicted.

- GOLD 3; Severe: FEV1 is 30\% - 49\% predicted.

- GOLD 4: Very Severe: FEV1 is below 30\% predicted.

- The peak expiratory flow rate (PEFR, also known as a peak flow) is the maximal rate that a person can exhale during a short maximal expiratory effort after a full inspiration. A normal PEFR does not exclude significant airflow obstruction. A value less than 80 of predicted is considered abnormal.

- $\quad$ MEF 25\% - 75\% - Maximal expiratory flow over the middle one-half of the FVC; the average flow from the point at which 25 percent of the FVC has been exhaled to the point at which 75 percent of the FVC has been exhaled.

\section{RESULTS}

1. Our study showed that in rural areas, $83.3 \%$ used mixed biomass fuel for cooking and $21 \%$ of women did not have a separate kitchen from living room, whereas $99 \%$ of urban women used Liquefied Petroleum Gas (LPG) for cooking and $100 \%$ urban women had a separate kitchen from living room.

2. Rural women without a separate kitchen had abnormal FEV1 $(p<0.003)$ and with abnormal PEFR, FEV1/FVC, MEF $25 \%$ - 75\% $(\mathrm{p}<0.001)$.

3. $30.9 \%$ rural women had respiratory symptoms with abnormal pulmonary function testing, whereas only $2.53 \%$ of urban women had respiratory symptoms.

4. In the present study, we found that $n-290(89.51 \%)$ of rural population and n- 77 (30.43\%) of urban population had abnormal FEV1, i.e. FEV1 < 80\% predicted which symbolises airflow limitation. On comparing both populations using Chi-square test, it was found to be statistically significant (P-value $<0.001$ ). FEV1 distribution is summarised below in Table 1 .

5. In the present study, we found that $n-41$ (12.65\%) of rural population and $n-0$ of the urban population had FEV1/ FVC ratio < 0.70, which symbolises airflow limitation. On comparing both populations using Chisquare test, it was found to be statistically significant ( $\mathrm{P}$ value $<0.001$ ) as summarised below in Table 2 .

6. PEFR value less than 80 of predicted are considered abnormal. PEFR was found lesser in rural population as compared to the urban population relating with the airflow limitation. On comparing both populations using Chi-square test, it was found to be statistically significant (P-value < 0.001). The PEFR comparison of rural and urban population is summarised below in Table 3.

7. MEF $25 \%$ - 75\% - Maximal expiratory flow over the middle one-half of the FVC. MEF $25 \%$ - $75 \%$ values less than $80 \%$ of predicted are considered abnormal and represent small airway obstructive pattern. These abnormalities are earliest obstructive changes to be detected on pulmonary function testing. The affected urban population could signify outdoor pollution. A comparative value of the rural and urban population is summarised below in Table 4.

\begin{tabular}{|c|c|c|c|c|}
\hline & & \multicolumn{2}{|c|}{ Population } & \multirow{2}{*}{ Total } \\
\hline & & Rural & Urban & \\
\hline \multirow[t]{2}{*}{ FEV1 } & $\geq 80$ & $\mathrm{n}-34(10.4 \%)$ & n-176 (69.57\%) & $n-210$ \\
\hline & $<80$ & $\mathrm{n}-290(89.51 \%)$ & $\mathrm{n}-77(30.43 \%)$ & $n-367$ \\
\hline \multicolumn{2}{|c|}{ Total } & n-324 & n-253 & n-577 \\
\hline \multicolumn{5}{|c|}{$\begin{array}{c}\text { P-value }<0.001 \\
\text { n- number in frequency, Chi-square test used } \\
\text { FEV1- Forced Expiratory Volume in } 1 \mathrm{Sec}\end{array}$} \\
\hline \multicolumn{5}{|c|}{ Table 1. Comparison of FEV1 (Rural v/s Urban) } \\
\hline
\end{tabular}

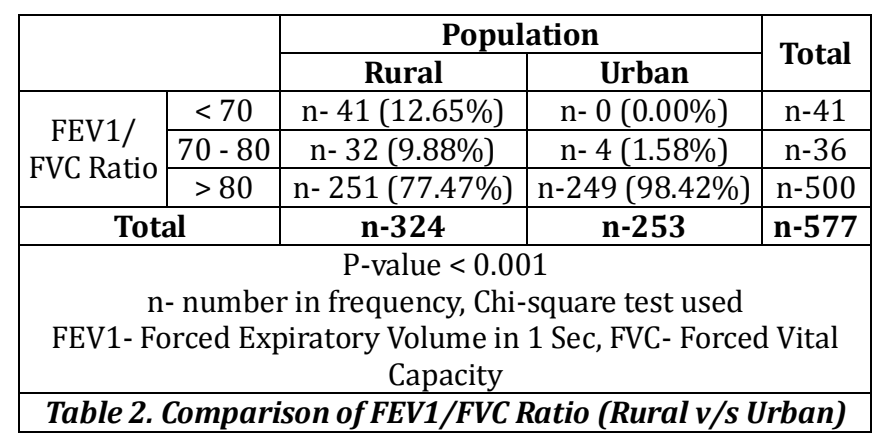

\begin{tabular}{|c|c|c|c|c|}
\hline & \multicolumn{2}{|c|}{ Population } & \multirow{2}{*}{ Total } \\
\hline & & Rural & Urban & \\
\hline \multirow{6}{*}{ PEFR } & $\leq 20$ & $\mathrm{n}-56(17.28 \%)$ & $\mathrm{n}-0(0.00 \%)$ & $\mathrm{n}-56$ \\
\hline & $21-40$ & $\mathrm{n}-121(37.35 \%)$ & $\mathrm{n}-13(5.14 \%)$ & $n-134$ \\
\hline & $41-60$ & $\mathrm{n}-83(25.62 \%)$ & $\mathrm{n}-41(16.21 \%)$ & $\mathrm{n}-124$ \\
\hline & $61-80$ & $n-41(12.65 \%)$ & $n-69(27.27 \%)$ & $n-110$ \\
\hline & $81-100$ & $\mathrm{n}-18(5.56 \%)$ & n-99 (39.13\%) & n-117 \\
\hline & $>100$ & n-5 (1.54\%) & n-31 (12.25\%) & $n-36$ \\
\hline \multicolumn{2}{|c|}{ Total } & $\mathrm{n}-324$ & $n-253$ & n-577 \\
\hline \multicolumn{5}{|c|}{$\begin{array}{c}\text { P-value }<0.001 \\
\text { n- number in frequency, Chi-square test used } \\
\text { PEF- Peak Expiratory Flow }\end{array}$} \\
\hline \multicolumn{5}{|c|}{$\begin{array}{l}\text { Table 3. Comparison of PEFR-Peak Expiratory Flow Rate } \\
\text { (Rural v/s Urban) }\end{array}$} \\
\hline
\end{tabular}




\begin{tabular}{|c|c|c|c|c|}
\hline & \multicolumn{2}{|c|}{ Population } & \multirow{2}{*}{ Total } \\
\hline & & Rural & Urban & \\
\hline \multirow{6}{*}{$\mathrm{MEF}_{25-75}$} & $\leq 20$ & $n-84(25.93 \%)$ & $n-00(0.0 \%)$ & $n-84$ \\
\hline & $21-40$ & n-97 (29.94\%) & $\mathrm{n}-7(2.77 \%)$ & $n-104$ \\
\hline & $41-60$ & n-70 (21.60\%) & $n-64(25.30 \%)$ & $n-134$ \\
\hline & $61-80$ & n-37 (11.42\%) & n-88 (34.78\%) & $n-125$ \\
\hline & $81-100$ & $n-22(6.79 \%)$ & n-68 (26.88\%) & $\mathrm{n}-90$ \\
\hline & $>100$ & $\mathrm{n}-14(4.32 \%)$ & n-26 (10.28\%) & $n-40$ \\
\hline \multicolumn{2}{|c|}{ Total } & n-324 & $n-253$ & n-577 \\
\hline \multicolumn{5}{|c|}{$\begin{array}{c}\text { P-value }<0.001 \\
\text { n- number in frequency, Chi-square test used } \\
\mathrm{MEF}_{25-75}-\text { Maximal Expiratory Flow } 25-75\end{array}$} \\
\hline \multicolumn{5}{|c|}{$\begin{array}{l}\text { Table 4. Comparison of MEF } 25-75 \text { - Maximal Expiratory Flow } \\
25-75 \text { (Rural v/s Urban) }\end{array}$} \\
\hline
\end{tabular}

\section{DISCUSSION}

Biomass is defined as the group of biologic materials (living organisms, both animal and vegetable and their derivatives) present in a specific area collectively considered. Some of this material is used as fuel for cooking or home heating. ${ }^{[12]}$ Close to $50 \%$ of the world's population, around 3 billion people, use biomass fuels as their primary source of domestic energy for cooking, home heating and light, ranging from near $0 \%$ in developed countries to more than $80 \%$ in China, India and Sub-Saharan Africa.[12-15] Our study showed that in rural areas, $83.3 \%$ used mixed biomass fuel for cooking in the form of wood, cow dung cakes etc.

In India, approximately 500,000 premature deaths, representing $6 \%$ to $7 \%$ of the national burden of disease may be attributable to indoor air pollution.[16]

A large number of mainly cross-sectional and case-control studies,[17, 18-22] have found an association of exposure to solid fuel smoke with COPD, chronic bronchitis, chronic airway disease and airflow obstruction, especially in women. The overall risk of COPD in women exposed to indoor air pollution from domestic solid fuel use, especially wood, estimated by Smith and co-workers[12] was consistently higher (OR, 3.2; 95\% CI, 2.3 - 4.8) than in men (OR, 1.8; 95\% CI, 1.0 - 3.2), who were likely less exposed. In our study, a majority of the rural women depend on biomass for cooking on daily basis in various forms increasing their risk for various cardiorespiratory and systemic disorders.

In a similar study like ours was conducted in Turkey where a highly significant $(p<0.00001)$ reduction of FEV1, FVC, FEV1/ FVC and FEF 25 - 75 was observed in case of biomass fuel users.[23]

In another similar study from India, the values of FEV1, PEFR and FEF 25 - 75 were significantly less ( $p<.01$ in FEV1 and $\mathrm{p}<.05$ in others) in wood users than the respective nonusers. When biomass users (either alone or in combination) were compared with nonusers, values of FEV1 $(\mathrm{p}<.05)$, FEV1\% $(\mathrm{p}<.01)$, PEFR $(\mathrm{p}<.05)$ and FEF $25-75(\mathrm{p}<.01)$ were significantly less in biomass fuel users. Similarly, only biomass fuel users were having significantly lower values of FEV1\% $(\mathrm{p}<.01)$, PEFR $(\mathrm{p}<.05)$ and FEF $25-75(\mathrm{p}<.01)$ in comparison to only LPG users and only wood users were having significantly lower values of FEV1\% $(p<.001)$ and FEF $25-75(p<.001)$ in comparison to only LPG users. The difference of PEFR values in the later case was also nearly significant $(\mathrm{p}=0.055)$ statistically.[24] Our study was found to be similar to the above studies, where we found that rural women exposed to biomass fuel exposure had abnormal FEV1 $(\mathrm{p}<0.003)$ and with abnormal PEFR $(\mathrm{p}<0.001)$, FEV1/FVC
( $\mathrm{p}<0.001)$ and MEF $25-75(\mathrm{p}<0.001)$ in comparison with urban women who used LPG for cooking.

A study which measured the effect of biomass burning on respiratory symptoms and lung function in rural Mexican women found that the population had $5.1 \%$ prevalence of asthma diagnosed by a physician, $23 \%$ were obese, $13 \%$ had an FEV1/ FVC $<70 \%$ and $37 \%$ reported having cough or phlegm most of the day.[25] In comparison, our study showed that $30.9 \%$ rural women had respiratory symptoms with abnormal pulmonary function testing, whereas only $2.53 \%$ of urban women had respiratory symptoms. The main respiratory symptoms noticed in our study were chest discomfort, cough or phlegm production and breathlessness.

A case-controlled study was undertaken to find out the possible relationship of biomass fuel and pulmonary tuberculosis. No association was found between type of fuel used and TB. However, it was found that low socioeconomic status, smoky rooms, the location of the kitchen, ventilation and associated respiratory symptoms during cooking are likely to be important contributors.[26] Our study showed that in rural areas, $21 \%$ of women did not have a separate kitchen from the living room which risks them for many chronic cardiorespiratory diseases including infectious disease like tuberculosis.

COPD is a major national health burden worldwide and is the 3rd leading cause of death worldwide as estimated by World Health Organisation (WHO).[27] A systematic analysis of the Global Burden of Disease Study 2016, COPD has been escalated as the 2 nd leading cause of death worldwide.[28] It is a great concern worldwide as the rural population in most of the population worldwide continue using biomass for cooking resulting in increased prevalence and burden of the disease.

WHO states that there is strong evidence that exposure to household air pollution can lead to a wide range of child and adult disease outcomes including acute and chronic respiratory conditions (e.g. pneumonia, chronic obstructive pulmonary disease), lung cancer, ischaemic heart disease, stroke and cataract. There is also supporting evidence suggesting exposure to household air pollution is linked with adverse pregnancy outcomes, tuberculosis, upper aerodigestive tract, cervical and other cancers.

Broader impacts of household energy are interrelated with poverty, environmental issues like global warming and deforestation, gender issues, health impact and income of family etc.

Improved ventilation of the cooking and living area can contribute significantly to reducing exposure to smoke. WHO has highlighted a number of ways to achieve better ventilation of the living environment including chimneys, smoke hoods (with flues), eaves spaces enlarged and repositioned windows (cooking window).

A study carried out by the Intermediate Technology Development Group (ITDG) has shown that appropriate lowcost interventions (smoke hoods, eaves spaces) could reduce smoke and personal exposures substantially in two rural communities in Kenya.[29]

Similar studies and initiatives are required worldwide, especially in developing country like India where a majority of the rural household relies on biomass fuel for cooking. 


\section{CONCLUSION}

Biomass fuel exposure poses a great challenge to growing economy, as it is continuously adding to the prevalence and burden of chronic cardiorespiratory diseases around the world. The escalation of COPD to world's second cause of death from third is a serious challenge to be tackled in the most innovative way.

The rural population which lacks adequate ventilation, proper housing designs, education and continued use of biomass fuel are at higher risk for development of COPD than counter urban population.

WHO has been taking initiative by various innovative techniques to develop technology to reduce the biomass exposure around the world, which needs to be supported and applied by respective government agencies and healthcare sectors.

A time has come when the thought of screening the rural population for COPD needs to be implemented, so as to reduce and check the silent growing population with COPD which would be a national threat in coming future.

\section{ACKNOWLEDGEMENT}

We thank our Pulmonary Function Technicians and Social Health Worker for all extended support provided by them.

\section{Abbreviations}

- $\quad$ FEV1- Forced Expired Volume in one second.

- $\quad$ FEV1/ FVC- Ratio of Forced Expiratory Volume in one second and Forced Vital Capacity.

- $\quad$ PEFR- Peak Expiratory Flow Rate.

- $\mathrm{MEF}_{25-75-}$ Maximal Expiratory Flow over the middle onehalf of the FVC.

- PM- Particulate Matter.

- $\quad$ COPD- Chronic Obstructive Pulmonary Disease.

- WHO- The World Health Organisation.

- $\quad$ LPG- Liquid Petroleum Gas.

- GOLD- Global Initiative for Obstructive Lung Disease.

- $\quad$ ATS- American Thoracic Society.

- ERS- European Respiratory Society.

- ITDG- Intermediate Technology Development Group.

\section{REFERENCES}

[1] Media Center: Household air pollution and health. Fact sheet $\quad \mathrm{N}^{\circ} 292 . \quad$ WHO 2016. http://www.who.int/mediacentre/factsheets/fs292/e $\mathrm{n} /$

[2] Balakrishnan K, Sankar S, Parikh J, et al. Daily average exposures to respirable particulate matter from combustion biomass fuels in rural households of southern India. Environ Health Perspect 2002;110(11):1069-75.

[3] Bruce N, Perez-Padilla R, Albalak R. Indoor air pollution in developing countries: a major environmental and public health challenge. Bull World Health Organ 2000;78(9):1078-92.

[4] Ezzati M, Kammen DM. The health impacts of exposure to indoor air pollution from solid fuels in developing countries: knowledge, gaps, and data needs. Environ Health Perspect 2002;110(11):1057-68.
[5] Larson TV, Koenig JQ. A summary of the emissions characterization and non-cancer respiratory effects of wood smoke. Washington DC: Environmental Protection Agency 1993.

[6] Zelikoff JT, Chen LC, Cohen MD, et al. The toxicology of inhaled woodsmoke. J Toxicol Environ Health 2002;5(3):269-82.

[7] Larson TV, Koenig JQ. Wood smoke: emissions and noncancer respiratory effects. Annu Rev Public Health 1994;15:133-56.

[8] Nolte CG, Schauer JJ, Cass GR, et al. Highly polar organic compounds present in wood smoke and in the ambient atmosphere. Environ Sci Technol 2001;35(10):1912-9.

[9] Data Accessed from Current Air pollution Control Board (CPCB) at Air Quality Monitoring Station. Navi Mumbai Municipal Corporation Airoli 15th May 2015. http://www.cpcb.gov.in/CAAQM/frmCurrentDataNew. aspx?StationName=NMMC\%20Airoli\&StateId=16\&Cit yId=310.

[10] Jindal SK, Aggarwal AN, Gupta D, et al. Indian study on epidemiology of asthma, respiratory symptoms and chronic bronchitis in adults (INSEARCH). Int J Tuberc Lung Dis 2012;16(9):1270-7.

[11] The global initiative for chronic obstructive lung disease (GOLD) report 2017. Online accessed on 2nd March 2017 from website http://goldcopd.org.

[12] Smith KR. Biofuels, air pollution, and health. New York: Plenum Press 1987.

[13] Desai M, Mehta S, Smith K. Indoor smoke from solid fuels: assessing the environmental burden of disease at national and local levels. Geneva, Switzerland: World Health Organization 2004.

[14] Smith KR, Mehta S, Maeusezahl-Feuz M. Indoor air pollution from household use of solid fuels: comparative quantification of health risks. In: Ezzati MLA, Rodgers A, Murray CJL, eds. Global and regional burden of disease attributable to selected major risk factors. Geneva, Switzerland: World Health Organization 2004:1435-93.

[15] World Resources Institute; United Nations Environment Programme; United Nations Development Programme; World Bank. World resources 1998-99: a guide to the global environment. Oxford UK: Oxford University Press 1998.

[16] Smith KR. National burden of disease in India from indoor air pollution. Proc Natl Acad Sci USA 2000;97(24):13286-93.

[17] Bruce N, Neufeld L, Boy E, et al. Indoor biofuel air pollution and respiratory health: the role of confounding factors among women in highland Guatemala. Int J Epidemiol 1998;27(3):454-8.

[18] Pandey MR. Domestic smoke pollution and chronic bronchitis in a rural community of the Hill Region of Nepal. Thorax 1984;39(5):337-9.

[19] Behera D. An analysis of effect of common domestic fuels on respiratory function. Indian J Chest Dis Allied Sci 1997;39(4):235-43.

[20] Dutt D, Srinivasa DK, Rotti SB, et al. Effect of indoor air pollution on the respiratory system of women using different fuels for cooking in an urban slum of Pondicherry. Natl Med J India 1996;9(3):113-7. 
[21] Behera D, Jindal SK, Malhotra HS. Ventilatory function in nonsmoking rural Indian women using different cooking fuels. Respiration 1994;61(2):89-92.

[22] Qureshi KA. Domestic smoke pollution and prevalence of chronic bronchitis/asthma in a rural area of Kashmir. Indian J Chest Dis Allied Sci 1994;36(2):6172.

[23] Sumer H, Turaclar UT, Onarlioglu T, et al. The association of biomass fuel combustion on pulmonary function tests in the adult population of Mid-Anatolia. Soz Praventivmed 2004,49(4):247-53.

[24] Saha A, Rao NM, Kulkarni PK, et al. Pulmonary function and fuel use: a population survey. Respiratory Research 2005;6:127.

[25] Regalado J, Pérez-Padilla R, Sansores R, et al. The effect of biomass burning on respiratory symptoms and lung function in rural Mexican women. Am J Respir Crit Care Med 2006;174(8):901-5.
[26] Behera D, Aggarwal G. Domestic cooking fuel exposure and tuberculosis in Indian women. Indian J Chest Dis Allied Sci 2010;52(3):139-43.

[27] Media Center: The top 10 causes of death. Fact sheet N³10. WHO 2017. http://www.who.int/mediacentre/factsheets/fs310/e n/

[28] Gakidou E, Afshin A, Abajobir AA, et al. Global, regional, and national comparative risk assessment of 84 behavioural, environmental and occupational, and metabolic risks or clusters of risks, 1990-2016: a systematic analysis for the Global Burden of Disease Study 2016. Lancet 2017;390(10100):1345-422.

[29] ITDG study on smoke, health and household energy in Kenya, Sudan and Nepal. WHO 2017. http://www.who.int/indoorair/interventions/itdg/en / 